\title{
Experimental investigation of enhancement of carbon dioxide foam stability, pore plugging, and oil recovery in the presence of silica nanoparticles
}

\author{
Abdul Rahim Risal ${ }^{1} \cdot$ Muhammad A. Manan $^{1} \cdot$ Nurudeen Yekeen $^{2} \cdot$ Nur Bashirah Azli $^{1} \cdot$ Ali Mohamed Samin $^{1}$. \\ Xin Kun $\operatorname{Tan}^{1}$
}

Received: 3 January 2018 / Published online: 28 November 2018

(c) The Author(s) 2018

\begin{abstract}
The influence of surface-modified silica $\left(\mathrm{SiO}_{2}\right)$ nanoparticles on the stability and pore plugging properties of foams in porous media was investigated in this study. The pore plugging ability of foams was estimated from the pressure drop induced during foam propagation in porous media. The results clearly showed that the modified $\mathrm{SiO}_{2}$ nanoparticlestabilized foam exhibited high stability, and the differential pressure increased in porous media by as much as three times. The addition of $\mathrm{SiO}_{2}$ nanoparticles to the foaming dispersions further mitigated the adverse effect of oil toward the foam pore plugging ability. Consequently, the oil recovery increased in the presence of nanoparticles by approximately $15 \%$ during the enhanced oil recovery experiment. The study suggested that the addition of surface-modified silica nanoparticles to the surfactant solution could considerably improve the conventional foam stability and pore plugging performance in porous media.
\end{abstract}

Keywords Foam $\cdot$ Pore plugging $\cdot$ Surface-modified nanoparticle $\cdot$ Enhanced oil recovery

\section{Introduction}

Gas injection involves the injection of carbon dioxide, methane, and nitrogen and other agents to dissolve and mobilize hydrocarbon components of crude oil (Orr 2005; Rossen and Bruining 2007; van Batenburg et al. 2010). Unfortunately, injection of steam or gas (carbon dioxide, nitrogen, and natural gas) into a reservoir results in a poor sweep efficiency (Rossen and van Duijn 2004; Farajzadeh et al. 2012). Gas injection also suffers from channeling, viscous fingering, and gravity overrides due to the reservoir heterogeneity and its low viscosity and density compared with the resident oil in the reservoir. The less viscous gases

Edited by Yan-Hua Sun

Abdul Rahim Risal

rahimrisa108@spe.petroleum.utm.my

1 Department of Petroleum Engineering, Faculty of Petroleum and Renewable Energy Engineering, Universiti Teknologi Malaysia, Johor Bahru, Malaysia

2 Institute of Hydrocarbon Recovery, Universiti Teknologi PETRONAS, Bandar Seri Iskandar, Perak, Malaysia have a greater tendency to finger through the existing highpermeability channel pathways or to rise to the top of the reservoir as a result of gravity override, resulting in premature gas breakthrough (Apaydin and Kovscek 2001; Pal et al. 2017). Hence, the concept of mobility control was proposed in order to mitigate gas fingering and gravity override (Yang and Reed 1989; Kharrat and Mahdavi 2012).

Foam flooding was introduced as an effective method to reduce the injected gas mobility (Bond and Holbrook 1958), especially carbon dioxide foam, due to the achievable miscibility and greenhouse gas control ( $\mathrm{Li}$ et al. 2016). Improvement in oil recovery due to high apparent viscosity and favorable flow behavior of foams in porous media has been reported in the results of previous studies (Rossen and Bruining 2007; Andrianov et al. 2012; Pal et al. 2017). Due to a significant reduction in gas and injected water mobility, the fluids were diverted from high-permeability zones to low-permeability upswept zones during the conventional foam (surfactant-stabilized foam) flow in porous media (Wang 1984; Alkan et al. 1991; Kim et al. 2005; Ashoori et al. 2012; Farzaneh and Sohrabi 2013). However, surfactant-stabilized foams are kinetically unstable and 
coalesce easily in porous media, especially in the presence of oil and in high-salinity and high-temperature environments (Bernard and Holm 1964; Kornev et al. 1999; Alargova et al. 2004; Rodriguez et al. 2007; Hunter et al. 2008). Consequently, a surfactant-silica nanoparticle combination has been recently introduced in order to generate durable foams and to address the limitations of the conventional surfactant-stabilized foams (Binks and Fletcher 2001; Binks 2002; Fujii et al. 2006; Hunter et al. 2009; Yekeen, et al. 2017a).

Theoretically, foam stabilization by nanoparticle-surfactant mixtures strongly depends on the properties of the nanoparticles, nanoparticle aggregation at the foam lamella, surfactant types, and the presence of the oil phase in the system. Particle hydrophobicity has been acknowledged as one of the critical factors influencing the stability of nanoparticle-stabilized foams. Results of previous studies show that super-stable foams were produced by partially hydrophobic nanoparticles of contact angles within the range of $60^{\circ}$ to $100^{\circ}$ (Marinova et al. 2002; Alargova et al. 2004; Binks and Horozov 2005; Kruglyakov et al. 2011; Yekeen et al. 2017b).

Dickinson et al. (2004) found that large yield stress of gel-like layer was formed by the adsorption and aggregation of partially hydrophobized silica nanoparticles at the foam lamellae which stabilized the generated foam. The nanoparticles further reduced the antifoam influence of oil by impeding the oil spreading at the gas-liquid interface of the foam. Binks and Horozov (2005) used fumed silica nanoparticles which have been hydrophobized to different extents using dichlorodimethylsilane. They found that the surface pressure of the foam reached a maximum value for silica nanoparticles with contact angles of $80^{\circ}-90^{\circ}$. The improved stability of the foam in the presence of nanoparticles was attributed to the effective attachment of nanoparticles at the foam interface. Yekeen et al. (2017b) provided a comparison between the foam stabilized by hydrophilic silica and 50\% methylsilyl-capped silica nanoparticles. They found that the moderately hydrophobic silica nanoparticle-stabilized foam was the most stable foam due to their thicker lamellae. The adsorption and accumulation of nanoparticles at the gas-liquid interface of the foam improved the static and dynamic stability of foam in porous media.

ShamsiJazeyi et al. (2014) studied the effect of polymermodified silica nanoparticles on foam flow in the Boise sandstone and found that the presence of partially hydrophobic polymer-modified silica nanoparticles increased the flow pressure drop. The flow of nanoparticlestabilized foam was modeled accounting for the nanoparticle/surfactant concentration ratio as part of the parameters (Worthen et al. 2015). The model predictions demonstrated the effectiveness of the pore plugging and fluid diversion by nanoparticle-stabilized foam. Some practical challenges of the nanoparticle-stabilized foam in field applications are the requirement of the high threshold shear rate for foam generation and nanoparticle agglomeration on pore spaces.

Partially hydrophobic silica nanoparticles are scarce because silica nanoparticles exist mainly as hydrophilic. Normally, to achieve the condition where silica nanoparticles can be termed as partially hydrophobic, the particles need to undergo surface wettability alteration. This can be done through surfactant adsorption where the particles are dispersed in a surfactant solution (Tiberg et al. 1999; Zhang and Somasundaran 2006; Zhang et al. 2008; Hunter et al. 2009; Carn et al. 2009; Cui et al. 2010; Fischer et al. 2012) or chemical modification (ligand exchange) on particle surfaces (Binks 2002; Dickinson et al. 2004; Kostakis et al. 2006; Rahman and Padavettan 2012; Wang et al. 2014). Despite some reported studies of the stability of nanoparticle-stabilized foams, the effects of surface-modified silica nanoparticles on dynamic foam stability and pore blocking performance in porous media are not yet understood. Most of the recent studies have been limited to bulk foam stability. Therefore, the objective of this research is to experimentally determine the effects of surface-modified silica nanoparticles on static and dynamic stabilities of conventional foams, and their pore blocking properties for EOR applications.

\section{Experimental}

\subsection{Materials}

Sodium dodecyl sulfate (SDS) is widely used as anionic surfactant. It was purchased from Scharlau Chemie (analytical grade, purity $>99 \%$ ). In this study, a $0.4 \mathrm{wt} \%$ SDS solution was used [above the critical micelle concentration (CMC)].

Non-treated bare silica dioxide $\left(\mathrm{SiO}_{2}\right)$ nanoparticles (surface hydrolyzed to $100 \% \mathrm{Si}-\mathrm{OH}$, purity $>99.5 \%$ ) and two surface-modified $\mathrm{SiO}_{2}$ nanoparticles, Silica A (surface hydrolyzed to $60 \% \mathrm{Si}-\mathrm{OH}$, purity $>96.3 \%$ ) and Silica B (surface hydrolyzed to $40 \%$, purity $>95.9 \%$ ), were all purchased from US Research Nanomaterials Inc. Silica A and Silica B were modified with different degrees of $\gamma$ aminopropyltriethoxysilane (APTES), resulting in different wettability depending on the hydrolyzed surface.

Phytagel, polysaccharide gellant (used as a gelling agent), and polydimethylsiloxane (PDMS) were purchased from Sigma-Aldrich. Paraffin oil was supplied by $\mathrm{QReC}$ Asia with a viscosity of $24 \mathrm{cP}$ and a density of $0.85 \mathrm{~g} / \mathrm{cm}^{3}$ at $25{ }^{\circ} \mathrm{C}$. $n$-decane (analytical grade) was provided by MERCK Group with a density of $0.73 \mathrm{~g} / \mathrm{cm}^{3}$ and a viscosity of less than $3 \mathrm{cP}$ at $25^{\circ} \mathrm{C}$. Carbon dioxide $\left(\mathrm{CO}_{2}\right.$, 
purity $>96 \%$ ) was supplied by Mega Mount Industrial Gases Sdn Bhd. All reagents were used without further purification.

Deionized water was used to prepare all solutions. The density, viscosity, and $\mathrm{pH}$ of deionized water were $1.0 \mathrm{~g} /$ $\mathrm{cm}^{3}, 1.0 \mathrm{cP}$, and 7 , respectively.

\subsection{Experimental methods}

\subsubsection{Silica nanoparticle hydrophobicity}

The SDS/silica nanoparticle solution was prepared by mixing silica with deionized water and later stirring at $2000 \mathrm{rpm}$ to ensure homogeneous dispersion before the addition of SDS. The $0.4 \mathrm{wt} \%$ SDS solution was then added to the homogeneous silica dispersion, and the dispersion was shaken at a low rate of $10-20 \mathrm{rpm}$ for $12 \mathrm{~h}$ to ensure homogeneity of the solution without producing foam.

The contact angle of $\mathrm{SiO}_{2}$ nanoparticles at the air-water interface was measured through the combination of gel trapping technique (GTT) and atomic force microscopy (AFM) proposed by Arnaudov et al. (2010). The detailed experimental procedures are as follows:

In GTT, $\mathrm{SiO}_{2}$ nanoparticles were spread at the air-surfactant interface containing dissolved $2 \mathrm{wt} \%$ phytagel at $50{ }^{\circ} \mathrm{C}$. The nanoparticle spreading process was conducted at a higher temperature to prevent a gelling effect of phytagel on $\mathrm{SiO}_{2}$ nanoparticles spreading at the air-surfactant interface. After the spreading process, the gelling process was conducted in a confine space at room conditions $\left(25^{\circ} \mathrm{C}\right.$ and $\left.1 \mathrm{~atm}\right)$. The gelling process was slow, allowing ample time for vertical trapping of $\mathrm{SiO}_{2}$ nanoparticles driven by the equilibrium contact angle. Once the gelling process was completed, liquid PDMS was poured over the gel containing trapped $\mathrm{SiO}_{2}$ nanoparticles. After the PDMS was cured, the PDMS gel was slowly peeled off along with silica nanoparticles. Particle protrusion, $h$, and average radius, $r$, were measured using a Nanowizard IV Nanoscience Atomic Force Microscope (JPK Instruments, Germany) with a scan area of $1 \mu \mathrm{m} \times 1 \mu \mathrm{m}$. The contact angle of $\mathrm{SiO}_{2}$ nanoparticles was calculated as:

$\theta=\cos ^{-1}\left(\frac{h}{r}-1\right)$

Static sessile drop shape analysis was also conducted by dropping a drop of the SDS solution on the prepared $\mathrm{SiO}_{2}$ nanoparticle sheet using a microsyringe. The drop shape was captured using a high-resolution camera Nikon D90 and Nikkor Micro Lens $60 \mathrm{~mm}$.

The detachment energy of $\mathrm{SiO}_{2}$ nanoparticles was estimated from the Gibbs adsorption equation. Particle detachment energy can be defined as the energy required to detach a particle of radius $r$ from the interface depending on the contact angle $(\theta)$ and the surface tension of the gasliquid interface $\left(\gamma_{\mathrm{gw}}\right)$.

$E_{\mathrm{d}}=\pi r^{2} \gamma_{\mathrm{gw}}(1-|\cos \theta|)^{2}$.

\subsubsection{Bulk stability of SDS/silica foams}

Static bulk foam stability was measured by using a $50-\mathrm{cm}-$ long graduated foam column. Fifty milliliters of sample solution was poured slowly into the cylinder. $\mathrm{CO}_{2}$ gas was injected at a flow rate of $0.05 \mathrm{~mL} / \mathrm{s}$ through the pores $(10-16 \mathrm{~mm})$ in the sintered disk which was attached to the bottom of the cylinder. Foam was generated for $5 \mathrm{~min}$, and the initial foam height was recorded after generation. Foam height was recorded for the duration of 20 min after generation. The $0.4 \mathrm{wt} \%$ SDS solution, above the CMC value $(0.23 \mathrm{wt} \%)$, was used to aid the attachment of $\mathrm{SiO}_{2}$ nanoparticles at the foam interface by lowering the surface tension to its minimum value.

\subsubsection{Pore plugging ability of SDS/silica foams}

A homogeneous glass-bead pack with porosity of 0.37 and permeability of $11 \mathrm{D}$ was used to measure the pore plugging pressure as shown in Fig. 1. After initial water saturation, the sample solution was injected at a flow rate of $0.5 \mathrm{~mL} / \mathrm{min}$ followed by foam at $0.05 \mathrm{~mL} / \mathrm{s}$ until the glassbead pack was filled with foam. After the pressure of the entire system reached equilibrium, water injection was started at a constant flow rate of $0.5 \mathrm{~mL} / \mathrm{min}$ and the pressures were recorded. The maximum pressure reading recorded was assigned as the maximum pore plugging pressure. After the pressure of the system reached a stable state, the experiment was repeated at liquid flow rates of $1.0,1.5$, and $2.0 \mathrm{~mL} / \mathrm{min}$, respectively. The procedure was repeated with a paraffin oil-saturated glassbead pack to investigate the effect of oil in pore plugging pressure. Paraffin oils with a viscosity of 3 and $24 \mathrm{cP}$ were used. The experiments were extended to investigate the effect of propagation distance to foam front on plugging ability. Initially, a $0.2 \mathrm{PV}$ foam front was injected at a flow rate of $0.5 \mathrm{~mL} / \mathrm{min}$ into the glass-bead pack and the pressure was recorded. After the pressure has reached equilibrium, a precisely $0.2 \mathrm{PV}$ water slug was injected at a flow rate of $0.5 \mathrm{~mL} / \mathrm{min}$ and the consequent pressure buildup was recorded. After the notable pressure build-up has reduced and stabilized, the experiment was continued with the injection of another $0.2 \mathrm{PV}$ water slug. The procedure was repeated until $0.8 \mathrm{PV}$ of cumulative water was injected. 


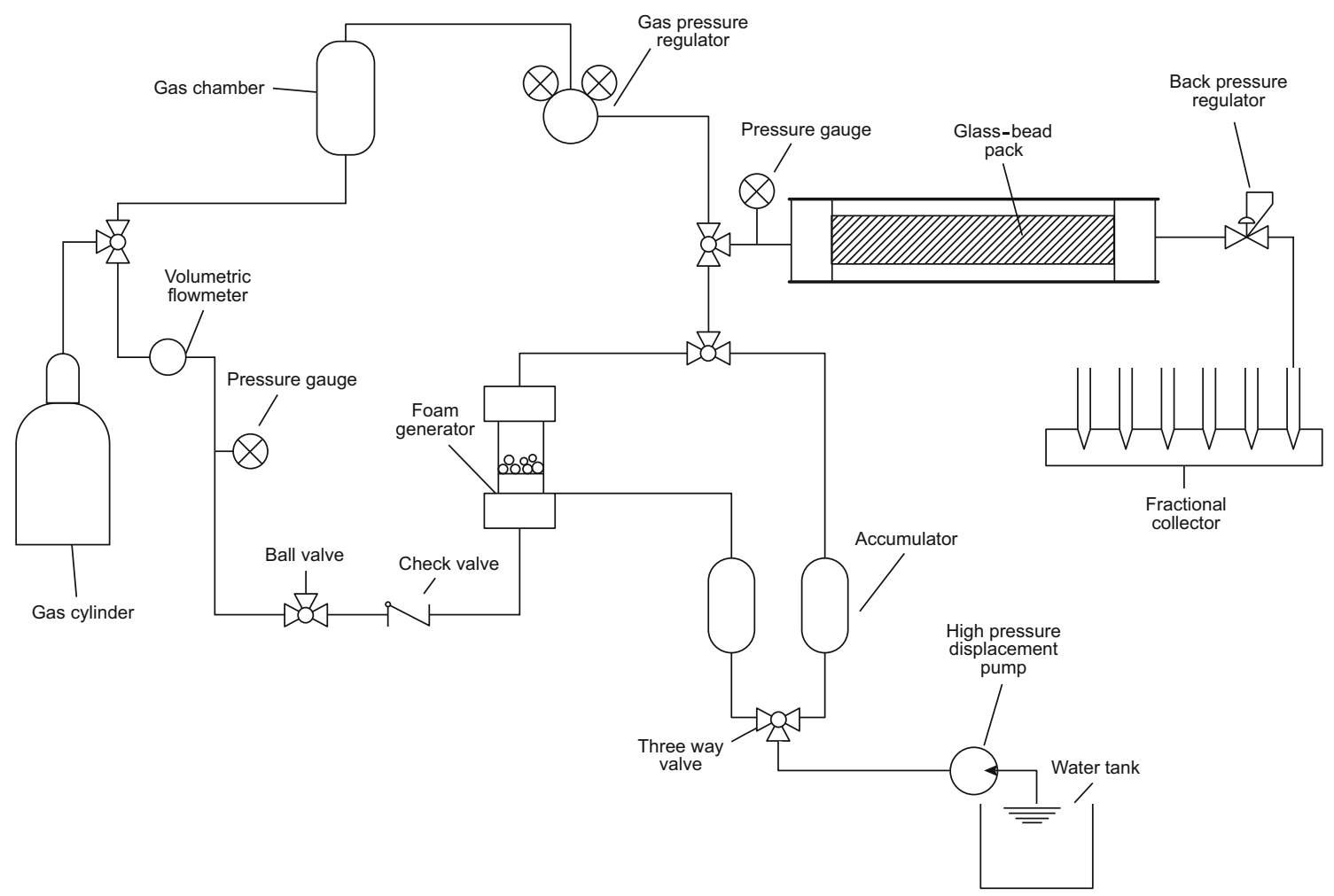

Fig. 1 Foam pore plugging and foam flooding experimental setup

\subsubsection{Application of SDS/silica foams in enhanced oil recovery}

A glass-bead pack of porosity 0.34 and permeability $1.9 \mathrm{D}$ (pore volume, $77 \mathrm{~mL}$ ) was used, replacing the earlier glassbead pack and assembled with the other apparatus as shown in Fig. 1. Initially, the glass-bead pack was preconditioned with 1.5 PV brine (salinity $30,000 \mathrm{ppm}$ ) injection. The brine was injected at a flow rate of $0.5 \mathrm{~mL} /$ min with a constant back pressure of 10 psi. Following the brine saturation, paraffin oil was injected at a flow rate of $0.5 \mathrm{~mL} / \mathrm{min}$ until the oil cut reached $98 \%$. Irreducible water saturation and initial oil saturation were estimated. Later, the fully oil-saturated glass-bead pack was reduced to residual oil through waterflooding. 1.2 PV of brine was injected at a flow rate of $0.5 \mathrm{~mL} / \mathrm{min}$ under a pressure drop of 2 psi. The residual oil saturation was calculated.

Gas flooding was started with an injection of carbon dioxide gas at a flow rate of $3.0 \mathrm{~mL} / \mathrm{min}$ under a pressure drop of 2 psi. The oil produced was carefully collected and measured and the gas injection was halted when significant oil production had ceased. The detailed experimental procedures are as follows: Foam flooding for residual oil was started after the glass-bead pack was waterflooded and oil saturation was reduced to residual oil saturation. $0.2 \mathrm{PV}$ of SDS solution was injected at a flow rate of $0.5 \mathrm{~mL} / \mathrm{min}$.
The purpose of the SDS solution injection was to mitigate the escaped carbon dioxide gas during pre-generated foam injection. 0.2 PV of pre-generated SDS foam was later injected at a flow rate of $0.05 \mathrm{~mL} / \mathrm{s}$. Subsequently, 0.6 PV of carbon dioxide gas was injected at a flow rate of $3.0 \mathrm{~mL} /$ min under 2 psi pressure drop. The SDS solution and pregenerated SDS foam were resupplied after $0.6 \mathrm{PV}$ of carbon dioxide gas had been injected. The foam flooding was halted when no further significant oil production was observed. The exact procedure was repeated for SDS/Silica A and SDS/Silica B. The produced oil was collected, and recovery result was calculated and compared to determine foam flooding effectiveness.

\section{Results and discussion}

\subsection{Contact angle of silica nanoparticles at foam interface}

Table 1 summarizes the contact angles and detachment energy measured by GTT-AFM and the static sessile drop method. Both methods show that bare $\mathrm{SiO}_{2}$ nanoparticles are strongly hydrophilic (Zargartalebi et al. 2015), while Silica A is weakly hydrophilic and Silica B is moderate hydrophobic. APTES bonded to the surface of $\mathrm{SiO}_{2}$ 
Table 1 Properties of silica nanoparticles

\begin{tabular}{llcccc}
\hline Name & Appearance and purity & \multicolumn{2}{l}{ Contact angle, degree } & & \multicolumn{2}{c}{ Range of detachment energy, kT } \\
& & GTT-AFM & Static sessile drop & GTT-AFM & Static sessile drop \\
\hline Bare silica & White powder, spherical, 99.5\% purity, hydrophilic & 20.0 & 28.5 & $0.12-0.3$ & $0.8-1.9$ \\
Silica A & White powder, spherical, 96.3\% purity, weak hydrophilic & 83.0 & 73.0 & $32.7-73.6$ & $21.0-47.0$ \\
Silica B & White powder, spherical, 95.9\% purity, hydrophobic & 130.0 & 105.0 & $5.4-12.1$ & $23.0-52.0$ \\
\hline
\end{tabular}

nanoparticles altered the nanoparticles from originally hydrophilic to weakly hydrophilic, and the difference in wettability of both surfaces of the modified $\mathrm{SiO}_{2}$ nanoparticles was attributed to the different degrees of alteration which is usually determined by the amount of Si$\mathrm{OH}$ left on the particle surfaces. Even though the finding is consistent for both methods, the contact angle results are significantly different as listed in Table 1.

Figure $2 \mathrm{a}$ depicts the result of the average particle protrusion, $h$, and the average equatorial radius, $r$, along with the cross section of the embedded Silica A nanoparticles, while Fig. 2b shows a drop of SDS solution on a Silica A sheet. The difference in contact angle greatly influenced the detachment energy of $\mathrm{SiO}_{2}$ nanoparticles as given in Table 1. Utilizing the contact angles measured by both methods, it was found that the detachment energy for
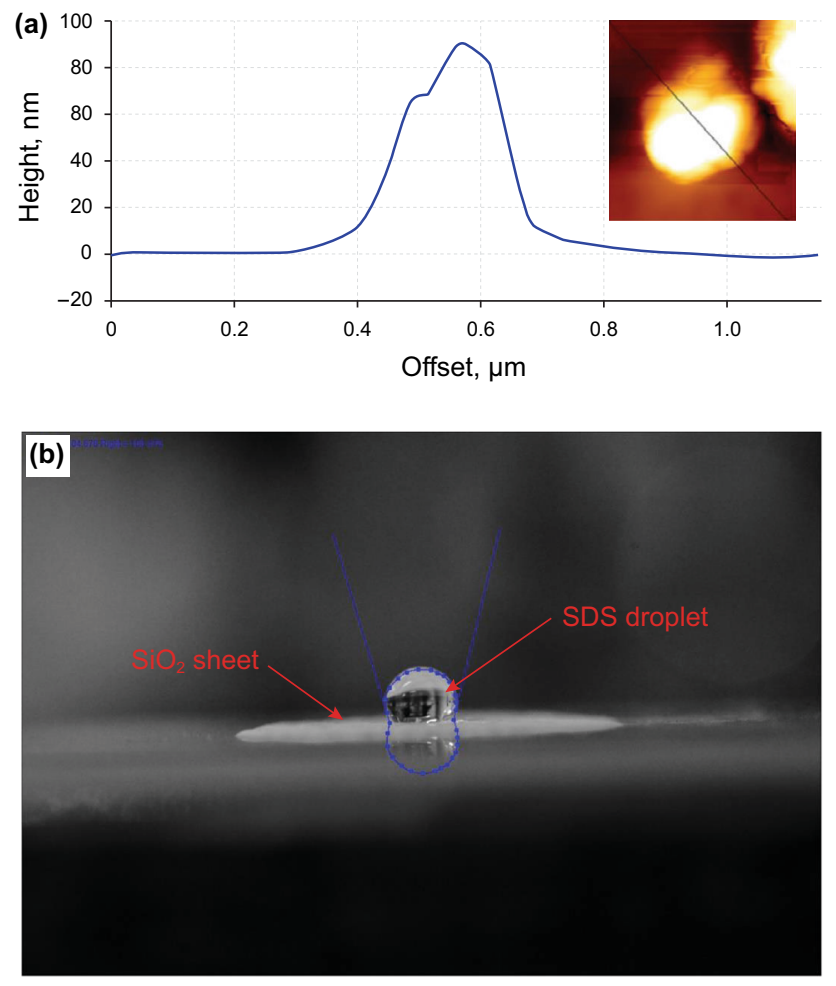

Fig. 2 a Atomic force microscopy of silica nanoparticles (Silica B) and cross section of silica nanoparticles (inset); b Drop shape analysis for silica nanoparticles (Silica B)
Silica A was higher for contact angle measured through GTT-AFM compared with the static sessile drop method. Bare silica and Silica B experienced a reduction in detachment energy, which agrees with Singh and Mohanty (2015). They found that, for a strong hydrophilic and hydrophobic nanoparticle, the resulting detachment energy is very low. Higher detachment energy indicates more effective $\mathrm{SiO}_{2}$ nanoparticles attached to the foam interface, which results in higher bubble stability. Compared with the drop shape analysis, the GTT-AFM technique is a more accurate method in determining the contact angle of silica nanoparticles at the foam interface (Arnaudov et al. 2010; Yekeen et al. 2018). Hence, the calculated detachment energy of $\mathrm{SiO}_{2}$ nanoparticles from the foam interface is more reliable.

Figure 3 shows the transmission electron microscopy (TEM) image of surface-modified Silica A nanoparticles. In addition to data provided by the manufacturer, the shape and radius of $\mathrm{SiO}_{2}$ nanoparticles were validated from the TEM image. The TEM image shows that the $\mathrm{SiO}_{2}$ nanoparticles are spherical in shape with a diameter of 20-30 nm.

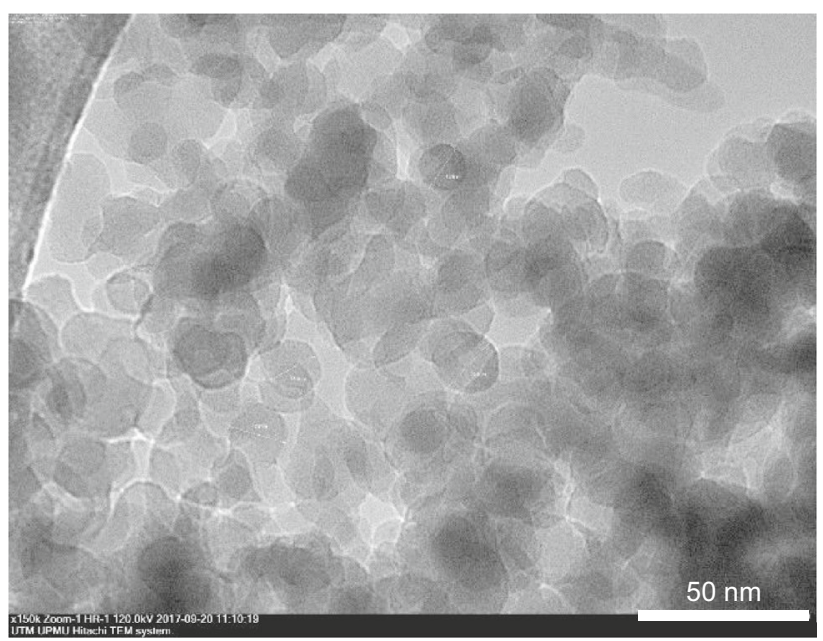

Fig. 3 TEM image of Silica A 


\subsection{Effect of surface-modified silica nanoparticles on static stability of SDS/silica foam}

Incorporation of $\mathrm{SiO}_{2}$ nanoparticles into the foaming solution was believed to improve the static foam stability (Binks 2002; Binks et al. 2007; Horozov et al. 2006; Carn et al. 2009; Singh and Mohanty 2015). From the preliminary results, the most stable foam for each type of $\mathrm{SiO}_{2}$ nanoparticles was found at a particle concentration of $0.01 \mathrm{wt} \%$. At a $\mathrm{SiO}_{2}$ nanoparticle concentration of $0.01 \mathrm{wt} \%$, foam stability was compared between the three types of silica nanoparticles as shown in Fig. 4. From the results, generally, the presence of silica nanoparticles improved static foam stability as shown by the lower volume of collapsed foam compared with the conventional SDS foam. A significant difference was also observed in the static stability of the foam generated with bare silica nanoparticles, Silica A nanoparticles, and Silica B nanoparticles.

Foam stabilized by bare silica (SDS/bare silica) was less stable compared with foam stabilized by Silica A (SDS/ Silica A) and Silica B (SDS/Silica B). Bare silica nanoparticles remained in the liquid phase due to their hydrophilicity, while weakly hydrophilic Silica A and hydrophobic Silica B nanoparticles resided firmly at the foam interface owing to their partial wettability. Better stability displayed by $\mathrm{SiO}_{2}$ nanoparticle-stabilized foam was attributed to the formation of a monolayer of bare $\mathrm{SiO}_{2}$ nanoparticles inside the liquid film and effective attachment of surface-modified $\mathrm{SiO}_{2}$ nanoparticles at the foam interface which had slowed down the liquid drainage (Lee et al. 2005; Horozov 2008; Yekeen et al. 2017a). In

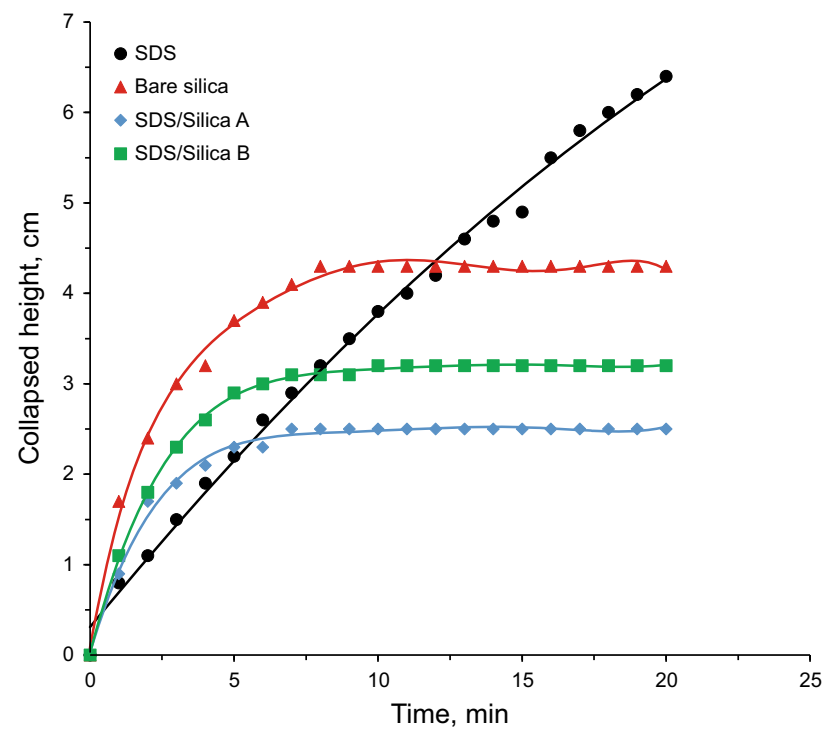

Fig. 4 Bulk foam stability in the presence of silica nanoparticles addition, the formation of a $\mathrm{SiO}_{2}$ nanoparticle monolayer provides electrostatic repulsion between two adjacent bubbles preventing them from coalescing (Hotze et al. 2010). However, continuous gravity-induced drainage eventually caused the destabilization of the formed monolayer, especially for SDS/bare silica foam. Due to their inability to withstand the hydrodynamic flow, the bare silica monolayer disintegrated and dragged away leaving blotches of uncovered foam film. The uncovered film is prone to rupture due to the increasing disjoining pressure previously hindered by the presence of electrostatic repulsion between silica particles. Conversely, the effective attachment of surface-modified $\mathrm{SiO}_{2}$ nanoparticles at the foam interface prevented the $\mathrm{SiO}_{2}$ nanoparticles from being dragged away by the liquid drainage. It further provided a prolonged steric barrier against coalescence and increasing surface elasticity, which is important in preventing foam coarsening (Yekeen et al. 2017a).

The difference in stability between SDS/Silica A foam and SDS/Silica B foam is further highlighted in Fig. 4. Further liquid recession has caused the bilayer rearrangement forming a bridging monolayer of nanoparticles. Bridging monolayer stability depends on the contact angle of nanoparticles at foam interfaces. When the contact angle is greater than $90^{\circ}$, the positive capillary pressure draws the adjacent film away from the nanoparticles during liquid drainage. For nanoparticles with contact angle less than $90^{\circ}$, further drainage causes the capillary to draw the fluid toward nanoparticles holding it in place and providing stability to the film (Singh and Mohanty 2015). Thus, it was observed that the SDS/Silica A foam had higher stability than the SDS/Silica B foam. The difference in bulk stability is observed in Fig. 5a-c, which shows the initial foam height and the height after the duration of the experiment. Foam stabilized by surface-modified $\mathrm{SiO}_{2}$ nanoparticles exhibited lower collapse compared with bare silica nanoparticle-stabilized foam.

The experiments were extended for foam generation of Silica A and Silica B dispersion without the presence of SDS solution. Apparently, without the aid of SDS, the foamability of the $\mathrm{SiO}_{2}$ nanoparticle dispersion is very low as depicted in Fig. 6. The stability measurement is practically impossible due to the extremely low volume of generated foam. However, the result does not necessarily portray the adverse effect of either Silica A or Silica B. It is believed such result is due to the high threshold flow rate to generate foam in the presence of nanoparticles. Without the presence of surfactant to reduce solution surface tension, foam generation required high mechanical energy to generate foam. Additionally, $\mathrm{SiO}_{2}$ nanoparticles cannot effectively attach to the foam surface due to the high attachment energy. Attachment energy can be defined as the energy required for the nanoparticle to attach itself at 

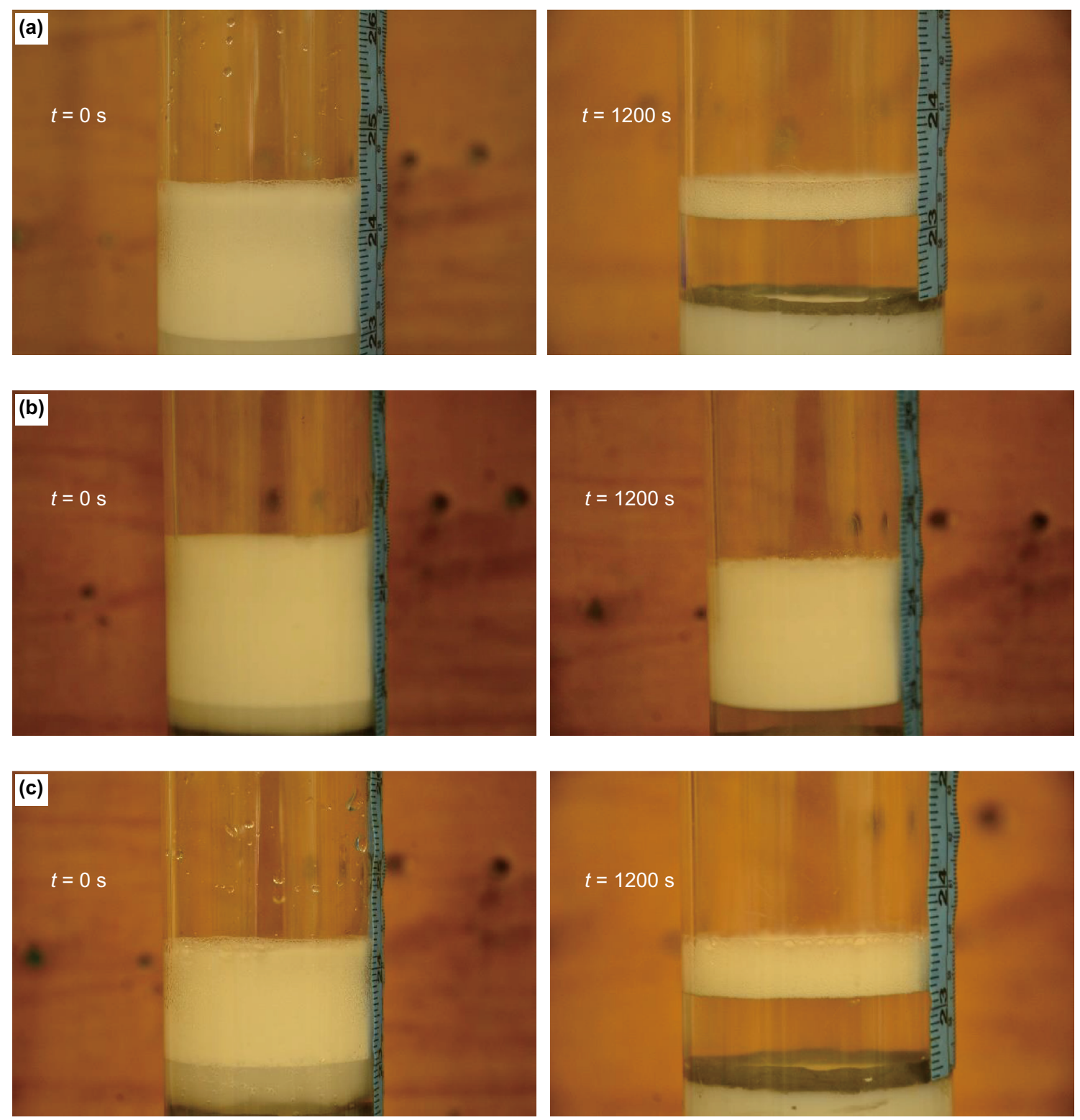

Fig. 5 Foam height in the presence of silica nanoparticles. a SDS/bare silica foam. b SDS/Silica A foam. c SDS/Silica B foam
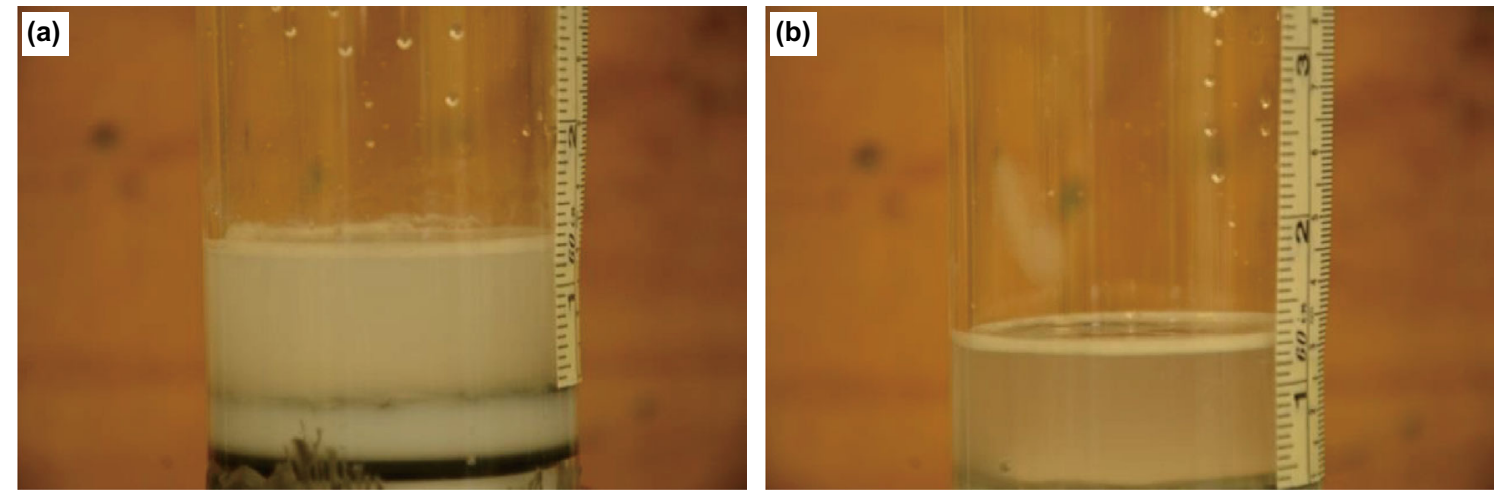

Fig. 6 Foam height in the presence of Silica A (a) and Silica B (b) 
the foam interface. Attachment energy like detachment energy is dependent on the solution surface tension. A higher gas shear rate is needed to generate foam. However, increasing the gas shear rate will induce catastrophic foam collapse where foam height is reduced in a short period of time. Therefore, it can be concluded that the designed method of foam generation is not suitable for foaming solution without the presence of SDS.

\subsection{Influence of surface-modified silica nanoparticles on pore plugging ability of SDS/silica foam}

Figure 7 shows the result of pore plugging pressure (pressure drop) for foams stabilized by various types of

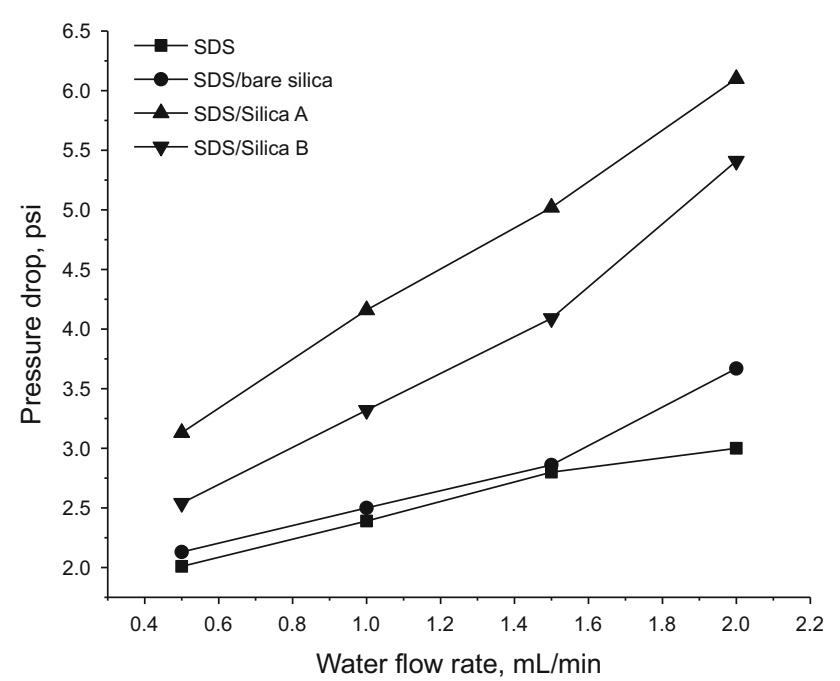

Fig. 7 Foam pore plugging pressure in porous media

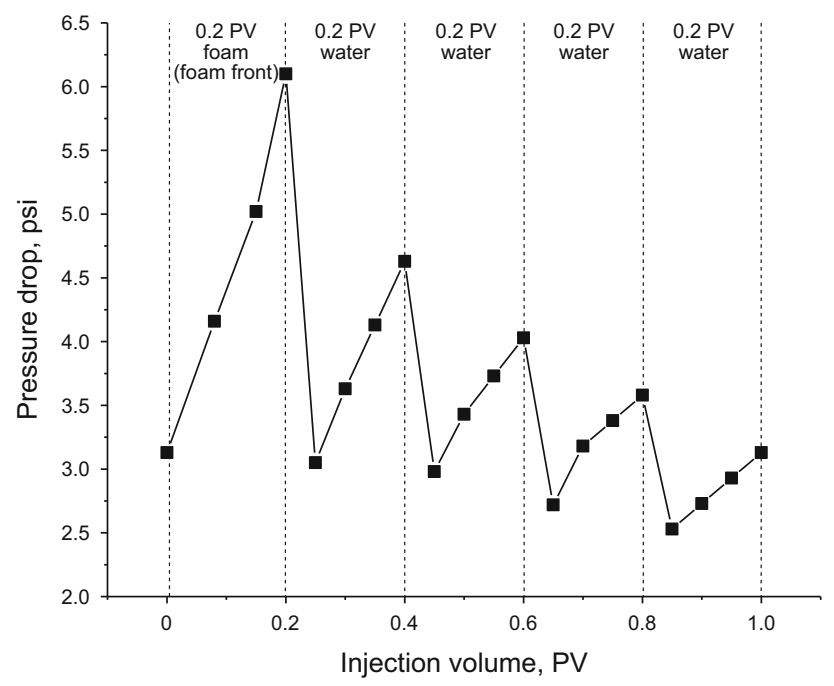

Fig. 8 Pore plugging pressure for propagated SDS/Silica A foam
$\mathrm{SiO}_{2}$ nanoparticles. Generally, the foam stabilized by $\mathrm{SiO}_{2}$ nanoparticles recorded a higher pressure drop compared with SDS-stabilized foam. The SDS/Silica A foam recorded the highest pore plugging pressure among the investigated $\mathrm{SiO}_{2}$ nanoparticles which is consistent with the higher bulk stability reported previously. The pore plugging pressure increased twofold compared with the SDS foam, indicating the prominent influence of Silica A on foam strength. Meanwhile, the pore plugging pressure recorded by the SDS/Silica B foam was second in the order and the SDS/Bare Silica foam third. Silica A nanoparticles offered higher structural stability and surface resistance to withstand surface distortion in porous media owing to the effective nanoparticle attachment, hence inducing a higher pore plugging pressure (Wang et al. 2014).

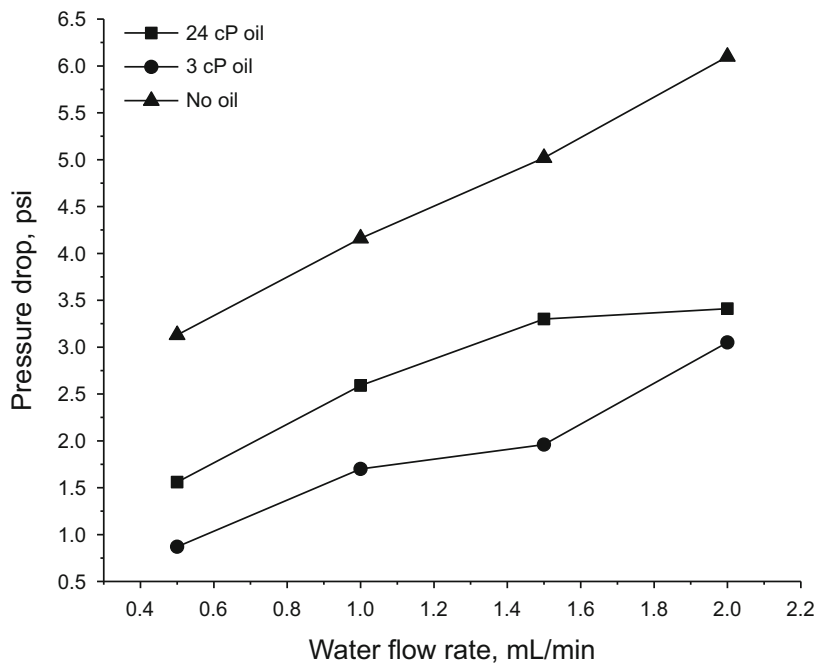

Fig. 9 Pore plugging pressure for SDS/Silica A foam in the presence of oil

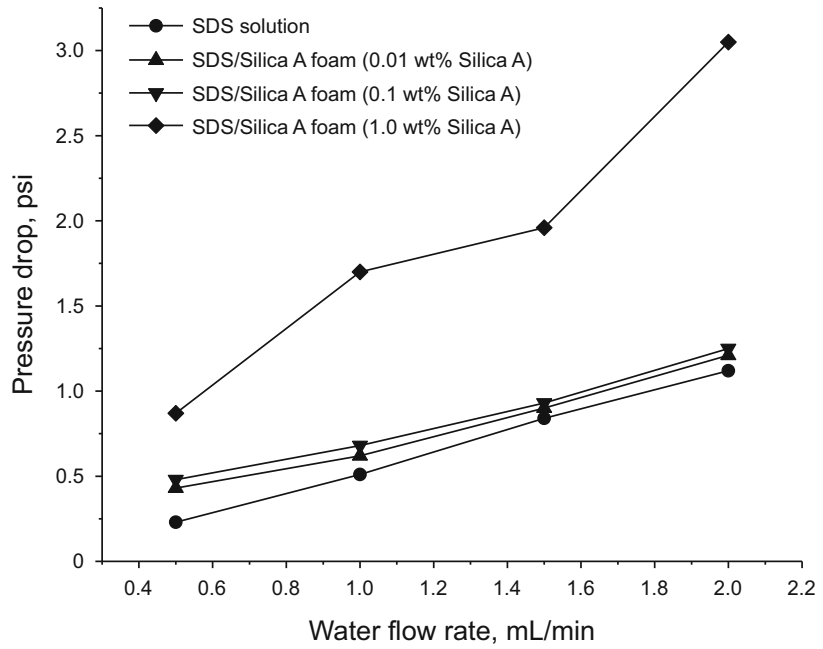

Fig. 10 Effect of Silica A concentration on the foam pore plugging pressure in the presence of low-viscosity oil $(3 \mathrm{cP})$ 


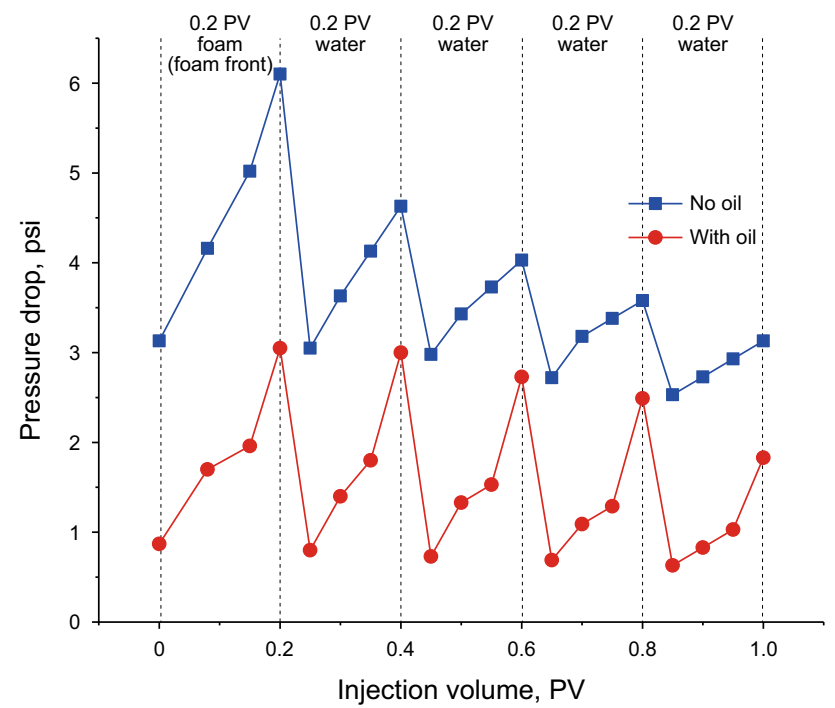

Fig. 11 Silica A foam propagation pressure in the presence of lowviscosity oil $(3 \mathrm{cP})$

A rigid Silica A monolayer covered the foam surface resisting the surface deformation during foam propagation. Unlike Silica B and bare silica, the Silica A monolayer remained on the foam surface providing resistance to the surface flow due to irreversible particle attachment. Resisting surface deformation caused an increment in foam flow pressure and was reflected in the foam pore plugging pressure (Wang et al. 2014). Figure 8 shows the pressure drop recorded as the foam propagated through the porous media at a flow rate of $0.5 \mathrm{~mL} / \mathrm{min}$. The foam pore plugging pressure was observed to decrease as foam front moved further away from the injection point. The continuous compression and decompression of foam as indicated by the pressure fluctuation led to diminishing foam strength. Diminishing foam strength eventually began to be reflected in a decreasing pressure drop.

\subsection{Effect of oil viscosity on SDS/silica foam performance}

The oil phase has been known to cause foam destabilization, which leads to a reduction in foam strength (Simjoo et al. 2013; Duan et al. 2014). Figure 9 shows the experimental results of pore plugging pressure for SDS/Silica A foam in the presence of oil. As can be observed, the pressure drop was significantly reduced for both $3 \mathrm{cP}$ and $24 \mathrm{cP}$ oil. The reduction was more profound in the presence of $3 \mathrm{cP}$ oil as the foam lost more than half of its original strength as indicated by a more than $50 \%$ reduction in pressure drop. This is due to the synergistic mechanism between oil bridging and oil spreading which destabilizes foam rapidly (Abdolahi et al. 2005; Yekeen et al. 2017a).

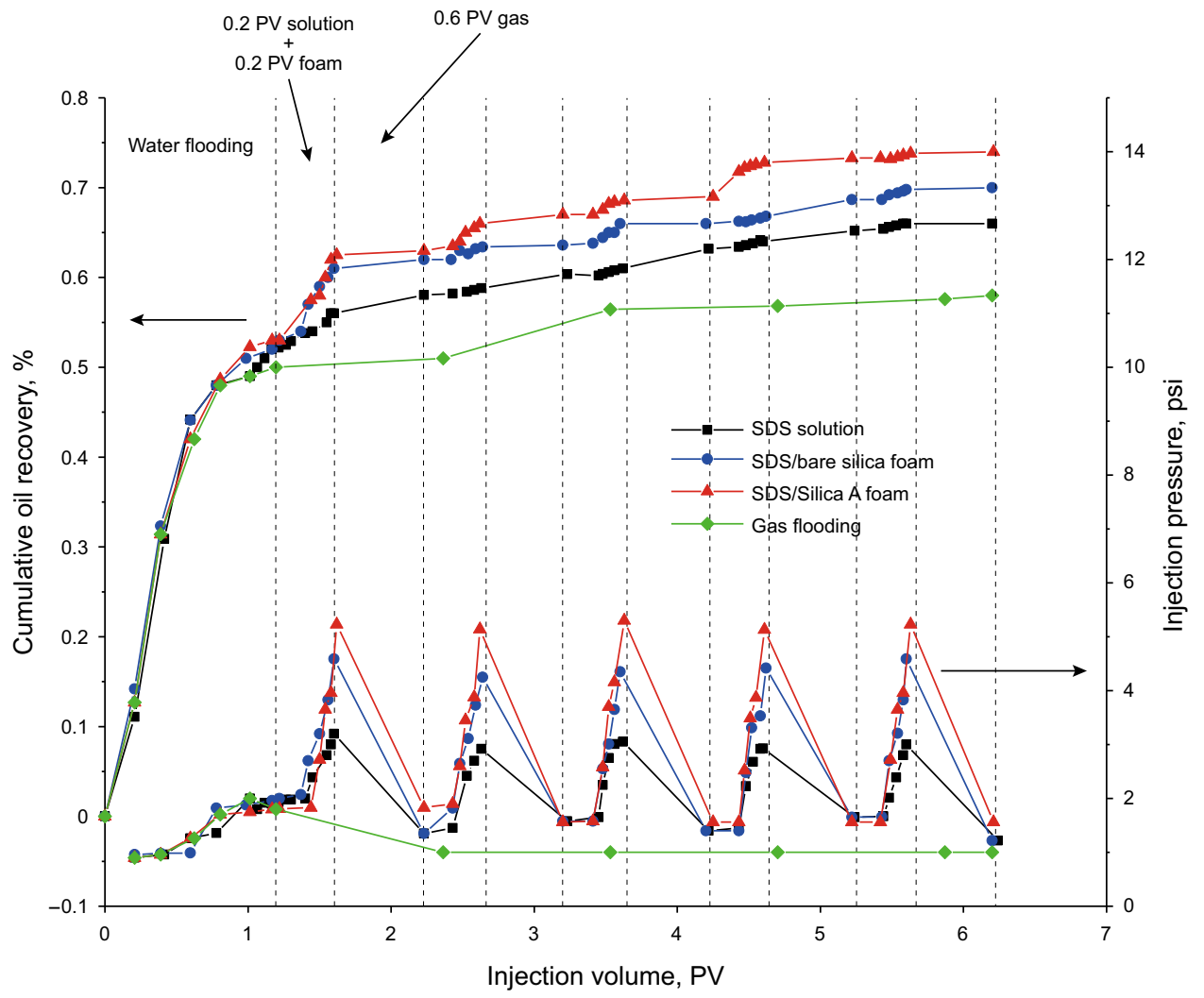

Fig. 12 Enhanced oil recovery by foam flooding 

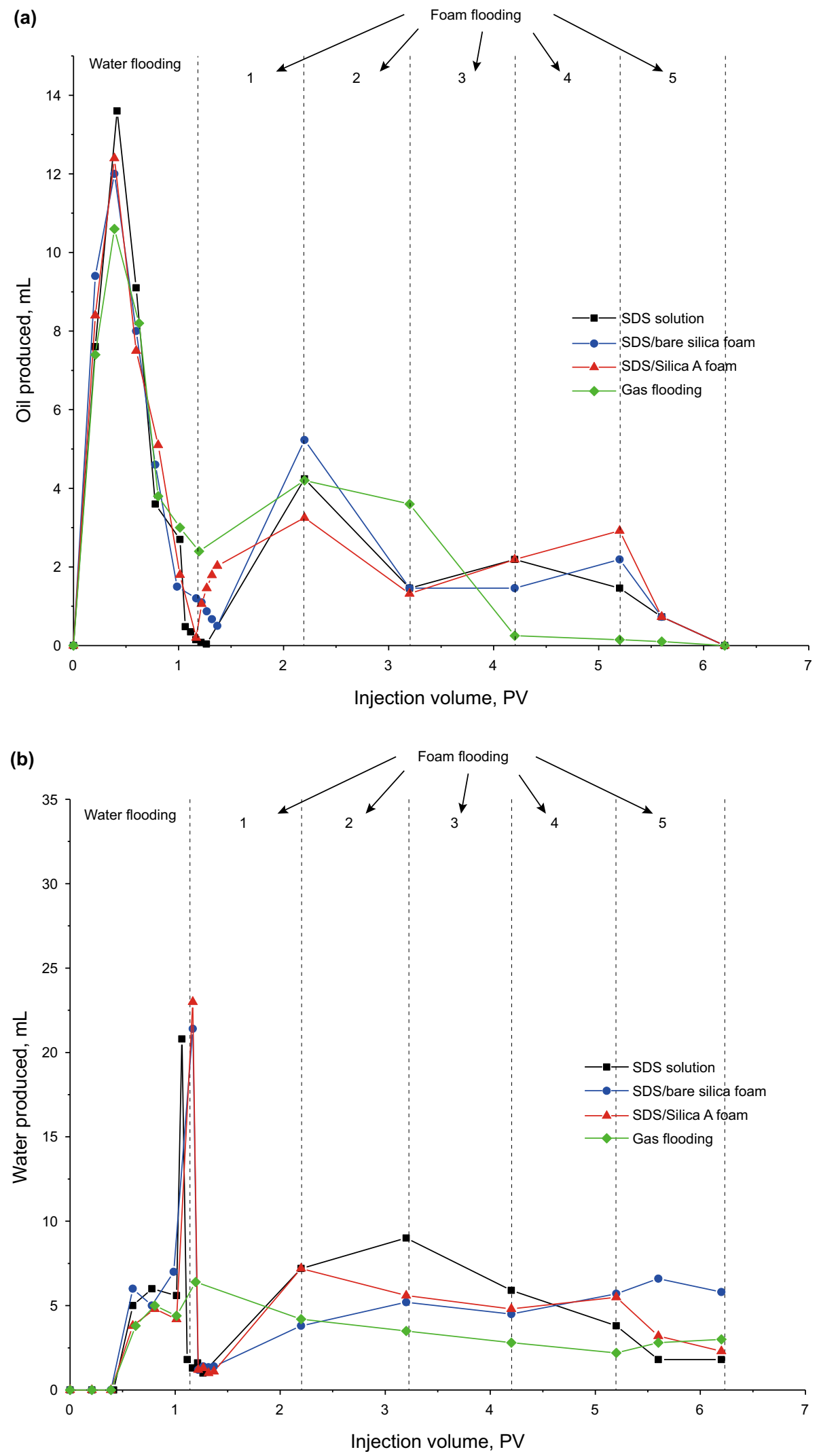

Fig. 13 Foam flooding. a Oil production. b Water production 
Figure 10 further shows the effect of $3 \mathrm{cP}$ oil on foam pore plugging pressure. The foam plugging pressure for $1.0 \mathrm{wt} \% \mathrm{SDS} /$ Silica A foam was as high as three times the plugging pressure registered by $0.01 \mathrm{wt} \%$ SDS/Silica A foam. Apparently, in the presence of oil, as the Silica A concentration increased, the pore plugging pressure increased accordingly, showing that a higher concentration of Silica A nanoparticles lessened the destabilization effect of oil. It is believed that at a higher concentration of Silica A nanoparticles a stronger and close-packed barrier is formed on the surface of the foam, preventing the oil spreading and the oil bridging that causes foam destabilization. Figure 11 depicts the foam propagation pressure through porous media in the presence of $3 \mathrm{cP}$ oil. In the presence of oil, foam registered a lower propagation pressure even though $1.0 \mathrm{wt} \%$ Silica A solution was used to stabilize the foam. The presence of $1.0 \mathrm{wt} \%$ Silica A nanoparticles was able to lessen the adverse oil effect, but the effect was still not fully mitigated.

\subsection{SDS/silica foam flooding enhancement}

Figure 12 shows the recovery profile for SDS/Silica A foam flooding. Initially, oil was recovered through waterflooding. 1.2 PV of brine was injected and $50 \%-55 \%$ of oil originally in place was recovered. Figure 13a dissects the oil production profile and indicates the oil production increased substantially for $0.6 \mathrm{PV}$ of water injected before starting to decline up until 1.2 PV where the oil production was almost zero. This is indicated by the hike in water production from Fig. 13b. Water breakthrough was observed at $0.6 \mathrm{PV}$ as indicated by the declining oil production and increasing water production. For this scenario, it is believed the water has bypassed the oil due to the unfavorable viscosity ratio. With the tremendous water output, the waterflooding was halted and foam flooding was commenced. The foam injection was indicated by the pressure surge shown in Fig. 12. Foam injection was done intermittently to ensure continuous presence of a foam front. Injection of foam reduced water production by as much as half as shown in Fig. 13b. A reduction in water production was accompanied by an increase in oil production as depicted in Fig. 13a. Therefore, it can be concluded that foam is ultimately very effective in increasing sweep efficiency.

From Fig. 12, the oil recovered by SDS/Silica A foam was higher than any other foam investigated. After waterflooding, $18 \%$ more of the residual oil was recovered by SDS/Silica A foam, with the ultimate oil recovery reaching $73 \%$. Figure 13a further shows the effectiveness of SDS/Silica A foam where the higher oil production was maintained until $5 \mathrm{PV}$ of gas injection. This was not achievable by gas flooding where the oil production was almost zero after 3.5 PV of gas was injected into the glassbead pack. Utilization of surface-modified silica nanoparticles has produced high foam stability which can be observed in the increasing oil recovery. The more stable foam has a capability to last longer and to improve the sweep efficiency without collapsing while in contact with the residual oil. This is due to the presence of irreversibly attached surface-modified silica nanoparticles that prevent oil from spreading and providing steric hindrance from the oil anti-foaming properties (Marinova et al. 2002; Binks and Horozov 2005; Yekeen et al. 2017b). Consequently, effective foam flooding was achieved, increasing the ultimate oil recovery.

\section{Conclusions}

From the results of this study, it can be concluded that the addition of surface-modified silica nanoparticles has substantially boosted the conventional foam stability. Owing to the high detachment energy, the insoluble silica nanoparticles were irreversibly placed at the foam interface, thus providing enhanced foam stability. Improved foam stability was also indicated from the higher plugging pressure and more effective pore plugging performance compared with the conventional SDS foam. In addition, the presence of effectively attached surface-modified silica nanoparticles is capable of mitigating the adverse effect of oil making foam flooding a favorable choice for residual oil recovery. From the residual oil recovery results, it was conclusively found that the surface-modified silica nanoparticle-stabilized foam has a better performance, recovering up to $18 \%$ of the residual oil. Evidently, the addition of surface-modified silica nanoparticles boosted the static and dynamic foam stabilities.

Acknowledgements The authors would like to thank the Ministry of Higher Education (Vot No. Q.J130000.2542.08H61) and Universiti Teknologi (UTM) Malaysia for supporting this research.

Open Access This article is distributed under the terms of the Creative Commons Attribution 4.0 International License (http://creative commons.org/licenses/by/4.0/), which permits unrestricted use, distribution, and reproduction in any medium, provided you give appropriate credit to the original author(s) and the source, provide a link to the Creative Commons license, and indicate if changes were made.

\section{References}

Abdolahi F, Moosavian MA, Vatani A. The mechanism of action of antifoams. J Appl Sci. 2005;5(6):1122-9. https://doi.org/10. 3923/jas.2005.1122.1129. 
Alargova RG, Warhadpande DS, Paunov VN, Velev OD. Foam superstabilization by polymer microrods. Langmuir. 2004;20(10):10371-4. https://doi.org/10.1021/la048647a.

Alkan H, Goktekin A, Satman A. A laboratory study of $\mathrm{CO}_{2}$-foam process for Bati Raman Field, Turkey. In: SPE Middle East Oil Show, November 16-19, Bahrain; 1991. https://doi.org/10.2118/ 21409-MS.

Andrianov A, Farajzadeh R, Mahmoodi NM, Talanana M, Zitha PLJ. Immiscible foam for enhancing oil recovery: bulk and porous media experiments. Ind Eng Chem Res. 2012;51(5):2214-26. https://doi.org/10.1021/ie201872v.

Apaydin OG, Kovscek AR. Surfactant concentration and end effects on foam flow in porous media. Transp Porous Media. 2001;43(3):511-36. https://doi.org/10.1023/A:1010740811277.

Arnaudov LN, Cayre OJ, Cohen SMA, Stoyanov SD, Paunov VN. Measuring the three-phase contact angle of nanoparticles at fluid interfaces. Phys Chem Chem Phys. 2010;12(2):328-31. https:// doi.org/10.1039/B917353F.

Ashoori E, Marchesin D, Rossen WR. Stability analysis of uniform equilibrium foam states for EOR processes. Transp Porous Media. 2012;92(3):573-95. https://doi.org/10.1007/s11242-0119921-8.

Bernard G, Holm L. Effect of foam on permeability of porous media to gas. SPE J. 1964;4(3):267-74. https://doi.org/10.2118/983PA.

Binks BP. Particles as surfactants-similarities and differences. Curr Opin Colloid Interface Sci. 2002;7(1-2):21-41. https://doi.org/ 10.1016/S1359-0294(02)00008-0.

Binks BP, Fletcher PDI. Particles adsorbed at the oil-water interface : a wettability and "Janus" particles. Langmuir. 2001;17(5):4708-10. https://doi.org/10.1021/la0103315.

Binks BP, Horozov TS. Aqueous foams stabilized solely by silica nanoparticles. Angewandte Chemie Int Ed. 2005;44(24):3722-5. https://doi.org/10.1002/anie.200462470.

Binks BP, Desforges A, Duff DG. Synergistic stabilization of emulsions by a mixture of surface-active nanoparticles and surfactant. Langmuir. 2007;23(14):1098-106. https://doi.org/10. 1021/la062510y.

Bond D, Holbrook O. Gas drive oil recovery process. US Patent. 1958; 630087.

Carn F, Colin A, Pitois O, Vignes-Adler M, Backov R. Foam drainage in the presence of nanoparticle-surfactant mixtures. Langmuir. 2009;25(9):7847-56. https://doi.org/10.1021/la900414q.

Cui ZG, Cui YZ, Cui CF, Chen Z, Binks BP. Aqueous foams stabilized by in-situ surface activation of $\mathrm{CaCO}_{3}$ nanoparticles via adsorption of anionic surfactant. Langmuir. 2010;26(20):12567-74. https://doi.org/10.1021/la1016559.

Dickinson E, Ettelaie R, Kostakis T, Murray BS. Factors controlling the formation and stability of air bubbles stabilized by partially hydrophobic silica nanoparticles. Langmuir. 2004;20(10):8517-25. https://doi.org/10.1021/la048913k.

Duan X, Hou J, Cheng T, Li S, Ma Y. Evaluation of oil-tolerant foam for enhanced oil recovery: laboratory study of a system of oiltolerant foaming agents. J Pet Sci Eng. 2014;122(October):428-38. https://doi.org/10.1016/j.petrol.2014.07.042.

Farajzadeh R, Andrianov A, Krastev R, Hirasaki GJ, Rossen WR. Foam-oil interaction in porous media: implications for foam assisted enhanced oil recovery. Adv Colloid Interface Sci. 2012;183-184:1-13. https://doi.org/10.1016/j.cis.2012.07.002.

Farzaneh SA, Sohrabi M. A review of the status of foam applications in enhanced oil recovery. In: EAGE annual conference and exhibition, June 10-13, London, 2013. https://doi.org/10.2118/ 164917-MS.

Fischer I, Morhardt C, Heissler S, Franzreb M. Partitioning behavior of silica-coated nanoparticles in aqueous micellar two-phase systems: evidence for an adsorption-driven mechanism from
QCM-D and ATR-FTIR measurements. Langmuir. 2012;28(45):15789-96. https://doi.org/10.1021/la303313m.

Fujii S, Iddon PD, Ryan AJ, Armes SP. Aqueous particulate foams stabilized solely with polymer latex particles. Langmuir. 2006;22(6):7512-20. https://doi.org/10.1021/la060812u.

Horozov TS. Foams and foam films stabilised by solid particles. Curr Opin Colloid Interface Sci. 2008;13(3):134-40. https://doi.org/ 10.1016/j.cocis.2007.11.009.

Horozov TS, Binks BP, Aveyard R, Clint JH. Effect of particle hydrophobicity on the formation and collapse of fumed silica particle monolayers at the oil-water interface. Colloids Surf A Physicochem Eng Aspects. 2006;282-283(July):377-86. https:// doi.org/10.1016/j.colsurfa.2005.11.085.

Hotze EM, Phenrat T, Lowry GV. Nanoparticle aggregation: challenges to understanding transport and reactivity in the environment. J Environ Qual. 2010;39(6):1909-24. https://doi. org/10.2134/jeq2009.0462.

Hunter TN, Pugh RJ, Franks GV, Jameson GJ. The role of particles in stabilising foams and emulsions. Adv Colloid Interface Sci. 2008;137(2):57-81. https://doi.org/10.1016/j.cis.2007.07.007.

Hunter TN, Wanless EJ, Jameson GJ, Pugh RJ. Non-ionic surfactant interactions with hydrophobic nanoparticles: impact on foam stability. Colloids Surf A Physicochem Eng Aspects. 2009;347(1-3):81-9. https://doi.org/10.1016/j.colsurfa.2008.12. 027.

Kharrat R, Mahdavi S. A comprehensive EOR study of a highly fractured matured field-case study. In: SPE Europec/EAGE annual conference, June 4-7, Copenhagen, Denmark, 2012. https://doi.org/10.2118/153311-MS.

Kim J, Dong Y, Rossen W. Steady-state flow behavior of $\mathrm{CO}_{2}$ foam. SPE J. 2005;10(4):17-21. https://doi.org/10.2118/89351-PA.

Kornev KG, Neimark AV, Rozhkov AN. Foam in porous media: thermodynamic and hydrodynamic peculiarities. Adv Colloid Interface Sci. 1999;82(1-3):127-87. https://doi.org/10.1016/ S0001-8686(99)00013-5.

Kostakis T, Ettelaie R, Murray BS. Effect of high salt concentrations on the stabilization of bubbles by silica particles. Langmuir. 2006;22(15):1273-80. https://doi.org/10.1021/la052193f.

Kruglyakov PM, Elaneva SI, Vilkova NG. About mechanism of foam stabilization by solid particles. Adv Colloid Interface Sci. 2011;165(2):108-16. https://doi.org/10.1016/j.cis.2011.02.003.

Lee HT, Neethling SJ, Cilliers JJ. Particle and liquid dispersion in foams. Colloids Surf A Physicochem Eng Aspects. 2005;263(1-3):320-9. https://doi.org/10.1016/j.colsurfa.2004. 12.064 .

Li DX, Zhang L, Liu YM, Kang WL, Ren SR. $\mathrm{CO}_{2}$-triggered gelation for mobility control and channeling blocking during $\mathrm{CO}_{2}$ flooding processes. Pet Sci. 2016;13(2):247-58. https://doi.org/ 10.1007/s12182-016-0090-9.

Marinova KG, Denkov ND, Tcholakova S, Deruelle M. Model studies of the effect of silica hydrophobicity on the efficiency of mixed oil-silica antifoams. Langmuir. 2002;18(17):8761-9. https://doi. org/10.1021/la025675p.

Orr FM. Theory of gas injection processes. Stanford: Stanford University; 2005.

Pal S, Mushtaq M, Banat F, Al Sumaiti AM. Review of surfactantassisted chemical enhanced oil recovery for carbonate reservoirs: challenges and future perspectives. Pet Sci. 2017;15(1):1-26. https://doi.org/10.1007/s12182-017-0198-6.

Rahman IA, Padavettan V. Synthesis of silica nanoparticles by solgel: size-dependent properties, surface modification, and applications in silica-polymer nanocomposites-a review. J Nanomater. 2012;2012(132424):1-15. https://doi.org/10.1155/2012/ 132424.

Rodriguez C, Anderez JM, Forgiarini A. Pulsating decay of some foam systems. Revista. 2007;28(3):135-40. 
Rossen W, Bruining J. Foam displacements with multiple steady states. SPE J. 2007;12(01):17-21. https://doi.org/10.2118/89397PA.

Rossen WR, van Duijn CJ. Gravity segregation in steady-state horizontal flow in homogeneous reservoirs. J Pet Sci Eng. 2004;43(1-2):99-111. https://doi.org/10.1016/j.petrol.2004.01. 004.

ShamsiJazeyi H, Miller CA, Wong MS, Tour JM, Verduzco R. Polymer-coated nanoparticles for enhanced oil recovery. J Appl Polym Sci. 2014;131(15):1-13. https://doi.org/10.1002/app. 40576.

Simjoo M, Rezaei T, Andrianov A, Zitha PLJ. Foam stability in the presence of oil: effect of surfactant concentration and oil type. Colloids Surf A Physicochem Eng Aspects. 2013;438(December):148-58. https://doi.org/10.1016/j.colsurfa.2013.05.062.

Singh R, Mohanty KK. Synergy between nanoparticles and surfactants in stabilizing foams for oil recovery. Energy Fuels. 2015;29(2):467-79. https://doi.org/10.1021/ef5015007.

Tiberg F, Brinck J, Grant L. Adsorption and surface-induced selfassembly of surfactants at the solid-aqueous interface. Curr Opin Colloid Interface Sci. 1999;4(6):411-9. https://doi.org/10.1016/ S1359-0294(00)00016-9.

van Batenburg DW, de Zwart AH, Doush M. Water alternating high pressure air injection. In: SPE improved oil recovery symposium, Apr 24-28, Tulsa, Oklahoma; 2010. https://doi.org/10. 2118/129882-MS.

Wang GC. A laboratory study of $\mathrm{CO}_{2}$ foam properties and displacement mechanism. In: SPE enhanced oil recovery symposium, Apr 15-18, Tulsa, Oklahoma, 1984. https://doi.org/10.2118/ 12645-MS.

Wang D, Hou Q, Luo Y, Zhu Y, Fan H. Blocking ability and flow characteristics of nitrogen foam stabilized with clay particles in porous media. J Dispers Sci Technol. 2014;36(2):170-6. https:// doi.org/10.1080/01932691.2013.856318.
Worthen A, Taghavy A, Aroonsri A, Kim I, Johnston KP, Huh C, et al. Multi-scale evaluation of nanoparticle-stabilized $\mathrm{CO}_{2}$-inwater foams: from the benchtop to the field. In: SPE annual technical conference and exhibition, Sept 28-30, Houston, Texas, 2015. https://doi.org/10.2118/175065-MS.

Yang SH. Reed RL. Mobility control using $\mathrm{CO}_{2}$ foams. In: SPE annual technical conference and exhibition, Oct $8-11$, San Antonio, Texas, 1989. https://dooi.org/10.2118/19689-MS.

Yekeen N, Manan MA, Idris AK, Samin AM, Risal AR. Experimental investigation of minimization in surfactant adsorption and improvement in surfactant-foam stability in presence of silicon dioxide and aluminum oxide nanoparticles. J Pet Sci Eng. 2017a;159(September):115-34. https://doi.org/10.1016/j.petrol. 2017.09.021.

Yekeen N, Idris AK, Manan MA, Samin AM, Risal AR. Bulk and bubble-scale experimental studies of influence of nanoparticles on foam stability. Chin J Chem Eng. 2017b;25(3):347-57. https://doi.org/10.1016/j.cjche.2016.08.012.

Yekeen N, Manan MA, Idris AK, Padmanabhan E, Junin R, Samin AM, et al. Comprehensive review of experimental studies of nanoparticles-stabilized foam for enhanced oil recovery. J Pet Sci Eng. 2018;2018(164):43-74. https://doi.org/10.1016/j.petrol. 2018.01.035.

Zargartalebi M, Kharrat R, Barati N. Enhancement of surfactant flooding performance by the use of silica nanoparticles. Fuel. 2015;143(March):21-7. https://doi.org/10.1016/j.fuel.2014.11. 040.

Zhang R, Somasundaran P. Advances in adsorption of surfactants and their mixtures at solid/solution interfaces. Adv Colloid Interface Sci. 2006;123-126(November):213-29. https://doi.org/10.1016/ j.cis.2006.07.004.

Zhang S, Sun D, Dong X, Li C, Xu J. Aqueous foams stabilized with particles and nonionic surfactants. J Colloid Surf A Physicochem Eng Aspects. 2008;324(1-3):1-8. https://doi.org/10.1016/j.col surfa.2008.03.020. 